\title{
Reworking research: interactions in academic articles and blogs
}

\author{
Hang Zou a, b, *, Ken Hyland b
}

a School of Foreign Languages, East China Normal University, China

b School of Education and Lifelong Learning, University of East Anglia, UK

E-mail: Hang.Zou@uea.ac.uk, K.Hyland@uea.ac.uk

\begin{abstract}
The blog is an increasingly familiar newcomer to the panoply of academic genres, offering researchers the opportunity to disseminate their work to new and wider audiences of experts and interested lay people. This digital medium, however, also brings challenges to writers in the form of a relatively unpredictable readership and the potential for immediate, public and potentially hostile criticism. To understand how academics in the social sciences respond to this novel rhetorical situation, we explore how they discoursally recontextualise in blogs the scientific information they have recently published in journal articles. Based on two corpora of 30 blog posts and 30 journal articles with the same authors and topics, we examine the ways researchers carefully reconstruct a different writer persona and relationship with their readers using stance and engagement (Hyland, 2005). In addition to supporting the view that the academic blog is a hybrid genre situated between academic and journalistic writing, we show how writers' rhetorical choices help define different rhetorical contexts.
\end{abstract}

Keywords: stance; engagement; academic blogs; journal articles; interaction

\section{Corresponding author}

Hang Zou

18 Uplands Court, Norwich, United Kingdom, NR4 7PH

Phone: 07594989321 Email: Hang.Zou@uea.ac.uk

\begin{abstract}
Author Biography
Hang (Joanna) Zou is a Ph.D. candidate in the school of foreign language, East China Normal University and a joint Ph.D. student at the University of East Anglia under the supervision of Professor Ken Hyland. Her current research interests include academic discourse analysis and Systemic Functional Linguistics.
\end{abstract}

Ken Hyland is Professor of Applied Linguistics in Education at the UEA. He is best known for his research into writing and academic discourse, having published over 240 articles and 28 books on these topics with 41,000 citations on Google Scholar. A collection of his work was published by Bloomsbury in 2018 . 


\section{Reworking research: interactions in academic articles and blogs \\ Hang Zou \& Ken Hyland}

\section{Introduction}

The explosion of digital technologies into every cranny of life in recent years has also brought profound changes to scholarly communication. Among the most significant of these changes has been the emergence of blogging as a means of increasing the visibility of both research and the researcher by taking science to a wider audience. While many science blogs are written by journalists, we restrict the term 'academic blog' here to refer to those written by active researchers and, more specifically, to those based on their own recently published research.

The extraction of some aspect of a text fitted into another text is called recontextualization, and the term helps explain how information can be appropriated and manipulated to reappear in another context (Bernstein, 1990; Linell, 1998). In this case, we are interested in how blogs require individuals to reformulate their published research for readers who might not otherwise read journal articles. In this way, writers can reach non-specialists in their discipline, share their opinions on disciplinary topics, receive the views of others on their work, and participate in new online scholarly communities. Here, then, is an emerging genre which facilitates a very different form of academic publishing to traditional channels.

This is, however, not only a genre requires new ways of presenting material, but new ways of relating it to readers, possibly demanding interactional strategies which contrast markedly with the often more reserved, author-evacuated conventions of much traditional research writing. Like personal blogs, the academic variety offer writers a space for self-expression and engagement with readers through asynchronous feedback. For academic researchers, then, stepping into this arena involves adopting a different academic persona to merge discourses which are neither entirely academic, as in 
research articles, nor completely popular, as in journalism (e.g Bondi, 2018). Blogs blur the boundaries between professional and general readers and require researchers to orchestrate a different set of interpersonal options in order to engage their readers and convey their ideas for maximum effect. In this paper, we explore these differences. Using Hyland's (2005) stance and engagement model, we compare key interactive features in 30 blog posts with those of 30 related research articles written by the same authors. Specifically, we address the following questions:

(1) How is the content of journal articles interpersonally recontextualized in blogs?

(2) What differences are there in the use of stance features in articles and blogs by the same authors?

(3) What differences are there in the use of engagement features in articles and blogs by the same authors?

\section{Academic blogs: functions, motives and rhetoric}

As academia becomes ever more integrated into the digital environment, researchers are increasingly engaging in alternative formats, with blogs dominating the new landscape. The academic blog is an online genre used by scholars to post their work, whether published or not, and discuss discipline-specific topics. With the aid of software affordances such as filtering tools for searching and accessing relevant material, hyperlinks to related research work and the availability of immediate commentary, academic blogging has expanded into an established channel of scholarly communication in both the physical and social sciences (e.g. Kurteeva, 2016). Encouraged by universities themselves as a means of promoting the institution, its research and its staff, blogs have become a key means of disseminating research, widening visibility and expanding outreach to the commercial and lay worlds.

Not only are they more accessible, both rhetorically and financially, than research papers, but blogs are also less top-down and one-way, providing a perpetual feedback loop of online communications (Andrews, 2003). Moreover, the fact that blogs potentially reach, and offer uptake to, large and diverse audiences make them a more 
egalitarian means of communicating academic research. Many non-experts want to hear about new findings from researchers rather than from journalists. By bypassing the traditional channels through which science is relayed to the public, they are claimed to further the 'democratization of science' (Mahrt \& Puschmann, 2014). For some, then, blogging is a way to demythologize science, allowing the public to see science during its manufacture, or thoughts in progress. Academic blogs have also been described as "virtual water coolers" (Kouper, 2010) around which a scholarly audience and the interested general public can join a discussion. McGrath (2016), for instance, shows how blogging in pure mathematics brought together contributors from a range of disciplines. Motives for blogging are also varied, but research shows they include promoting one's research, or more broadly, one's field to potential audiences, facilitating idea-sharing and making researchers feel connected (Gross \& Buehl, 2015; Mahrt \& Puschmann, 2013; Smart, 2016).

Blogs therefore provide writers with an opportunity to summarize and promote papers they have published in scientific journals which may not easily be available to the public. But while academic blogs perform a variety of functions for their users, they continue to co-exist with traditional venues of scholarly communication and popular scientific journalism, neither replacing nor entirely mimicking them. The fact that writers seek to present ideas to a heterogeneous audience of specialists and lay people means they avoid the lengthy, sustained argumentation of the journal article, to offer a more succinct and reader-friendly presentation. Academic blogs are generally seen as more intimate and responsive than research articles, scientific letters and other published formats (e.g. Mauranen, 2013; Trench, 2008; Walker, 2006). On the other hand, in hard science blogs, a great deal of the content is often beyond the complete layperson and some knowledge of the issues is often necessary (Tokar et al, 2012). They have therefore been characterized as hybrid texts where various genres are brought together and reformulated to suit new target audiences (Gotti, 2014).

By breaking down boundaries between public and private discursive practices, blogs 
therefore give shape to a more informal style which makes fewer demands on readers' subject knowledge and specialized interests. Discursive strategies therefore tend to construe immediacy, affectivity, shared goals, and social support (Luzón,2011). Moreover, the fact that readers can come back at the writer and engage with the issues to criticize and dispute claims, sometimes fiercely with blunt criticism, sarcasm and condescension (Luzón, 2013b), means posting research work can be a fraught endeavor. As Blanchard (2011) puts it:

on science blogs, people actively engage with the issues at hand, ask questions, express disapproval, while the blogger does not merely pontificate but is confronted with real-life.

For these reasons then, we might expect academic bloggers to go about their presentations in ways which present themselves, their work and their readers in ways that allow for more direct and spontaneous writer-reader exchanges.

Applied linguists have explored some of the discourse features used to do this, focusing on both blogs and the discussion threads which follow them, indicating a blending of discursive interpersonal strategies from different genres (Luzón, 2011, 2018; Mauranen, 2013; Bondi, 2018). Luzón's (2011) study, for instance, found both affect and conflict are construed through discursive strategies such as affectivity, in-group cohesiveness, group exclusion, and confrontation. Mauranen (2016) emphasized the role of discourse reflexivity in academic blogs to increase readers' reflection on language and sharedness while Luzón (2013a) analyzed the strategies used by bloggers to tailor information to engage readers. Luzón (2018), in fact, suggests that the use of non-standard language enables research groups to more effectively share information, while Bondi (2018) stresses the importance of intertextuality in conveying information in economic blogsOverall, these researches stress the hybridity of academic blogs which combines features from scholarly written and spoken genres such as journal papers, conference talks and social media discourses (Grafton, 2009; Lehti, 2011; Mauranen, 2013). 
Given this hybridity, the question arises of how the ideas, interpretations and research discoveries codified in peer approved journal papers find their way into blogs, emerging as material which has personal relevance, or perhaps general interest value, to a wider readership. Recontextualisation means that changing aspects of the communicative purpose of the text requires changes in the text itself, and here this means reformulating knowledge from an article to a blog post. But we are less concerned with how expert knowledge is recontextualised for a, probably, largely lay audience than with the reworking of interpersonal language strategies to reframe writer-reader interaction for this new environment.

Surprisingly little research has addressed how research papers are recontextualized and repackaged in academic blogs. Researchers have chosen instead to focus on blogs themselves and how these wield the authority of science for multiple audiences (e.g. Luzón, 2013a). But many blog posts start their lives as research articles and both the presentation of facts and the argument forms of professional science change considerably in its repackaging. Such changes go beyond simplifying materials for a wider audience but involve a discursive reconstruction of scientific knowledge which necessarily impacts a range of features, not least how writers express a stance and engage their readers.

In this paper we aim to address this gap by focusing on the interpersonal language choices made by the same authors moving between the two genres, exploring how they tailor their discourse for audiences with different knowledge and processing needs. Rather than compare the decisions of individual authors at specific points in their papers, however, we explore the genre differences which authorial choices create. This approach is less concerned with the on-line processing of writing and more with the different purposes for which language is being used. The comparative analysis will, we hope, shed light on how blogs work to convey academic information and contribute to our understanding of the ways different contexts and purposes shape rhetorical choices. 


\section{Mapping interactions: the stance and engagement framework}

Academic writing is widely acknowledged to embody interactions between writers and readers, so that writers do not only take a novel point of view towards some theory or aspect of the world, but also anticipate readers' imagined reactions to those views. So writing is, at least in part, an interactive accomplishment which involve both the writer's self-representation and positioning in relation to the issues they discuss but also his or her alignment with readers. As such, writers seek to create a recognizable social world which allows them to conduct interpersonal negotiations and balance claims for the significance, originality and plausibility of their work against the convictions and expectations of their readers (Hyland, 2005; Hyland \& Jiang, 2016).

Analysts have invested considerable effort in trying to identify the ways that writers use language to acknowledge and construct social relations as they negotiate agreement of their claims with readers (e.g. Biber, 2006; Gray \& Biber, 2012; Martin \& White 2005). One widely used model is that of stance and engagement (Hyland, 2005) which offers a framework for probing writer-reader interactions. For Hyland, stance and engagement are two sides of the interactional coin, stance being a writer-oriented, attitudinal dimension and engagement concerning reader-oriented alignment.

Stance refers to "an attitudinal dimension including features which refer to the ways writers present themselves and convey their judgments, opinions and commitments." (Hyland, 2005, p. 176). Specifically, there are four key stance resources writers can adopt to stamp their personal authority onto their arguments: (Hyland, 2001):

- Hedges withhold complete commitment to a proposition and open a discursive space where readers can dispute interpretations.

- Boosters help writers present their work with assurance and shut down alternative voices.

- Attitude markers indicate the writer's affective, rather than epistemic, attitudes to propositions, conveying surprise, agreement, frustration etc.

- Self-mention is the writer's intrusion in the text through use of first-person to 
emphasize their contributions.

Engagement, on the other hand, concerns the ways:

writers acknowledge and connect to others, recognizing the presence of their readers, pulling them along with their argument, focusing their attention, acknowledging their uncertainties, including them as discourse participants, and guiding them to their interpretations.

(Hyland, 2005, p. 176).

Here writers explicitly intrude into their texts to meet the expectations of audiences and connect to readers through:

- Reader mention bring readers into a discourse, normally through second person pronouns

- Directives are instructions to the reader, mainly expressed through imperatives and obligation modals.

- Questions invite direct collusion by addressing the reader as having an interest in an issue and a willingness to follow the writer's response.

- Shared knowledge are signals asking readers to recognise something as familiar or accepted.

- Personal asides comment on what has been said, adding to the writer-reader relationship.

Together these features offer a way of revealing how writers represent their positions, convey information and persuade their readers of its reliability. Now we turn to describe our corpora and methods.

\section{Data and analysis}

To trace how writers recontextualize the contents of their published journal articles as academic blogs, we compiled two corpora comprising 30 blog posts corresponding to 30 previously published research articles written by the same authors on the same topics. This helps to eliminate any possible idiosyncratic preferences of writers by 
aggregating features of the texts, allowing us to see the typical characteristics of the genres themselves rather than of the authors. The posts were selected from the popular LSE Impact Blog website. ${ }^{1}$ This site, hosted by the London School of Economics and Political Science, was one of the earliest academic venues, launching its first blog in 2010 (Elmes 2012), and is now one of the world's most influential and prestigious hubs in the social sciences for the exchange of research findings and discussion of research trends. Today it is a major forum for scholars seeking to maximize the impact of their research in subjects like policy, society and education, bringing diverse voices and stakeholders together to introduce their work and discuss research issues.

The site is monitored and submitted posts undergo a review process by the editors to ensure novelty, interest and readability and are generally published on the site within two weeks after they are revised. Each post has a limit of 1,000 words and the audiences, according to the website, primarily comprise researchers, higher education professionals, policymakers, research funders, students and those generally interested in the issues raised. The website claims that more than 70,000 unique users read the blog posts and their commentaries each week.

We collected blogs from the LSE website which met the following criteria:

1) Published within a five-year period from 2013 to 2018 so as to ensure currency;

2) Posts were related to a recently published journal article by the same author on the same topic;

3) The journal articles were published in peer-reviewed journals in the social sciences. In total, the academic blog corpus comprised 30 texts of 31,089 words and the journal article corpus was 30 papers of 180,666 words (see Table 1). We believe the difference in the word counts of the two corpora had little influence on our results as the number of texts in each corpus was the same. More crucially, we were not looking for discourse organizing features such as interactive resources (such as we now turn to or in the next

\footnotetext{
${ }^{1}$ LSE website address: http://blogs.lse.ac.uk/impactofsocialsciences/
} 
section) which vary according to the length of the text. Instead, we focused on interactional resources in the recontextualisation process which are less influenced by text length.

Table 1 Corpus size and composition

\begin{tabular}{lcc}
\hline & Number of texts & Total number of words \\
\hline Academic blog posts & 30 & 31,089 \\
Journal articles & 30 & 180,666 \\
\hline
\end{tabular}

The two corpora were searched for Hyland's (2005) stance and engagement features using AntConc (Anthony, 2018). The search inventory comprised a general list of common stance and engagement features and additional items were added after a thorough reading of the data. Next, all retrieved items were manually checked to ensure that each performed the function to which it was assigned. A $10 \%$ sample was independently coded by both authors with an inter-rater agreement of $96 \%$. Intrareliability tests were also conducted by each author re-categorizing $20 \%$ of the cases two weeks after the initial coding with full agreement between the first and second categorizations achieved. Finally, the frequencies of features in each category were calculated after normalising the results to 1,000 words to allow for cross-corpora comparison. The frequencies for each stance and engagement feature in our corpora were analysed using SPSS to determine statistical significances. The results will be discussed in the following sections.

\section{Writer-reader interaction across genres}

Overall, we found 2469 devices in the blogs and 10,245 in the - much longer - articles. When normed for text length, this amounted to 68.65 stance items per 1,000 words in the blogs compared with 50.14 in the article corpus, and 10.78 engagement features per 1,000 words in the blogs and 6.55 in the articles. The details are presented in Table 2. 
The results suggest that researchers seem conscious of the need to signal a stance towards their topic and engagement with their readers when writing in the two genres. It is not surprising to find that there are significantly more interactive features in the blog posts than in the articles $(\log$ Likelihood $=31.15, \mathrm{p}<0.01$ for stance and log Likelihood $=9.51, \mathrm{p}<0.01$ for engagement), with engagement features being particularly heavily represented in the blogs with $61 \%$ more examples than in the articles. The results also indicate that academics draw on the full range of interactional devices. These are determined by both the target audiences and rhetorical purposes of each genre: broadly speaking, to inform general readers of scientific information or to gain credit for their research claims. In the following sub-sections, results specific to each category of stance and engagement features will be discussed.

Table 2 Stance and engagement features in the two genres (per 1,000 words \& \%) Academic blog posts Journal articles

\begin{tabular}{lcccc} 
& per 1,000 words & $\%$ & per 1,000 words & $\%$ \\
\hline Hedges & 24.77 & 36.08 & 20.63 & 41.15 \\
Boosters & 14.99 & 21.84 & 12.16 & 24.25 \\
Attitude markers & 18.50 & 26.94 & 10.27 & 20.47 \\
Self-mentions & 10.39 & 15.14 & 7.08 & 14.13 \\
Total & $\mathbf{6 8 . 6 5}$ & $\mathbf{1 0 0 . 0 0}$ & $\mathbf{5 0 . 1 4}$ & $\mathbf{1 0 0 . 0 0}$ \\
& & & & \\
Reader pronouns & 5.31 & 49.25 & 1.99 & 30.37 \\
Directives & 1.48 & 13.73 & 1.87 & 28.44 \\
Questions & 2.35 & 21.79 & 0.51 & 7.85 \\
Shared knowledg $\epsilon$ & 1.58 & 14.63 & 2.16 & 33.00 \\
Personal asides & 0.06 & 0.60 & 0.02 & 0.34 \\
Total & $\mathbf{1 0 . 7 8}$ & $\mathbf{1 0 0 . 0 0}$ & $\mathbf{6 . 5 5}$ & $\mathbf{1 0 0 . 0 0}$ \\
\hline
\end{tabular}

\section{The expression of stance}


In presenting an academic argument, writers make linguistic choices to convey judgements, opinions, and degrees of commitment to what they say, boosting or toning down claims and criticisms, expressing surprise or importance, and inserting themselves into the text (Hyland, 2004). It has to be said that stance is far less apparent in academic than many other registers (e.g. Biber \& Finegan, 1989) and Table 2 shows a significantly higher frequency of all stance markers in the blogs, particularly in attitude markers, with $80 \%$ more cases than articles.

\subsection{Hedges and boosters}

Hedges and boosters either downplay or strengthen a writer's commitment to a proposition, modifying its scope, relevance or certainty (Hyland, 2005). Their use reaffirms the role of writer-reader interaction in academic discourses by signaling the writer's explicit intrusion into a text to make a judgement about what is being discussed.

Table 2 shows that hedges are the most frequent stance resource for writers in both the blogs and articles, supporting research which shows academic writing to be extensively hedged (Biber, 2006; Hyland, 1998). Hedges are rational strategies for dealing with academic interactions as they mark appropriate scholarly caution, indicating that a statement is based on the writer's plausible reasoning rather than certainty; an assessment of the status of knowledge in a text which indicates the writer's position towards the claim itself and the reader's possible reaction to it. Hedges therefore signal an awareness of opposing viewpoints and seek to minimize potential criticism, as here:

(1) This explains, to some extent, why young women would be less likely to study STEM subjects, but not why more advantaged young women seem to be more resilient to these effects. $(\mathrm{BP} 6)^{2}$

(2) Our work suggests a possible additional piece to the causal story on why democracy matters; (BP28)

\footnotetext{
2 BP refers to the blog post corpus and RA the research article corpus and the number identifies the text.
} 
The fact hedges were significantly more frequent in the blogs than journal articles (log Likelihood $=6.07, \mathrm{p}<0.05)$ reflects the more interactive and evaluative nature of blogs and perhaps acknowledges the fact readers can respond, publicly and immediately, below the post. It is not news that online venues often see considerable verbal hostility (e.g. Kleinke, 2008) and even academic mailing lists can generate sarcasm, insults and personal attacks (Angouri and Tseliga, 2010). Myers (2010) points out that bloggers and commenters have a reputation for casual rudeness and, in a corpus of academic blog responses on scienceblogs.com, a multidisciplinary science hub, Luzón (2011, 2013b) found disagreement expressed through criticism, irony, sarcasm, condescension, challenging questions and insults, concluding:

In blog discussions interlocutors explicitly engage in the adversarial method of argument, where one's claims are defended by showing that the other party is wrong. This involves engaging in argument that is more overt, explicitly antagonistic and personal than in most academic genres.

(Luzon, 2013b: 118).

As in many other online forums, blog comments construe both relations of solidarity and confrontation, and responders seem to use impoliteness to convey group allegiance and construct identities which support the position of one group against another (Angouri \& Tseliga, 2010). Many commenters may have an axe to grind against a writer or the group he or she represents, so participation may be a channel for abuse or criticism from those who do not share the writer's opinions. Deferring to the views of readers using hedges in such circumstances may be a necessary survival strategy.

(3) To my knowledge, no one has asked or answered this question in any discipline, and yet it is an important question. (BP8)

(4) Based on these data, it seems that ResearchGate rewards participation in the platform. (BP13)

So the high frequency of hedges in this genre is perhaps a result of the fact that blogs 
enter an arena which is openly evaluative with opportunities for responders to assert their own contra-stance and solidarity with alternative views. Writers thus seem to take great care to avoid the potential risk of being too assertive and incurring harsh criticism by trying to win over their readers with heavily mitigated statements. It is also likely that the use of hedges acknowledges the potential for disagreement from a more heterogeneous readership whose views it is difficult to predict.

While hedges tone down commitment or assertiveness, boosters indicate certainty and, perhaps surprisingly given what we have just said, they are also significantly more frequent in the blogs $(\log$ Likelihood $=11.2, p<0.01)$. In journal articles research knowledge is carefully machined in reserved tones for a peer audience, readers who are generally familiar with both the prior understandings of the discipline which have led to this point and with the conventions of scholarly argument which values a certain circumspection and modesty. When transforming this knowledge into a blog, writers have no such assurances and must construct a dialogue across discursive domains. In speaking to a wider, less predictable audience, writers cannot assume that their readers will always recognize the significance of information in the same way as insiders and so relevance has to be supplied in the text itself rather than presupposed in the context. This means that the original claims are often strengthened and supplemented, in our data at least, with additional appeals which adjust new information to readers' assumptions and values. Boosters can play a part in this:

(5) The results of this study could be extremely useful in closing the gender gap in access to STEM subjects as a whole. (BP6)

(6) Undoubtedly, the economics undergraduate degree is very healthy in the UK overall, but not everywhere in the UK and not for everyone who wants to study economics. (BP25)

Boosters help remove any doubts about claims and upgrade propositions to emphasize their significance, uniqueness or originality (Hyland, 2005). They can therefore play a 
role in convincing readers of the likely validity of statements, but in closing down potential opposition they also run the risk of attracting criticism and the ire that the use of hedges is designed to suppress. Boosters, then, are a potentially perilous strategy, but one often worth taking. Moreover, we find the most prevalent boosters are what Vassileva (2001) calls 'belief boosters' (7 and 8) such as in my view, I believe which express a much higher degree of commitment than 'solidarity boosters' ( 9 and 10) which are more common in articles:

(7) I'm talking about citizen science, and I think it could transform the terms on which science and society meet. (BP 24)

(8) Although ISI listing is seen by many to imply a quality stamp, in our view it should not matter where research is published. (RA27)

(9) In fact, the current situation is far more complex. (RA15)

(10) This obviously involves removing tags from the HTML and control characters from the PDF. (RA11)

Belief boosters carry the assurance of the writer's conviction, a stamp of personal authority and approval to help arouse reader involvement and carry the asserted claims through individual commitment. These boosters contrast markedly with those seeking to engage readers by invoking the shared understandings of a specialized readership which requires no elaboration as a result of their insider knowledge.

Blog writers, therefore, seem to face a balancing act. They must juggle the need to hedge against the criticisms of a broader and potentially less restrained audience which is able to respond publicly and instantly, and boosting claims which do not benefit from readers' subject knowledge familiarity.

\subsection{Attitude markers}


Writers also express their attitudes to what they are discussing significantly more in blogs than in journal articles ( $\log$ Likelihood $=32.13, \mathrm{p}<0.01)$. Almost any choice among related words is evaluative, of course, but we are interested here in explicit signals of affective assessment and personal feeling (Hyland, 2005). Hood (2010), using an Appraisal model, found little affect in research articles and here we encountered the greatest difference between the two genres, with $80 \%$ more cases per 1000 words in the blogs.

Unlike research papers in many fields, the credibility of the writer and material is not constructed through adherence to norms of authorial reticence and the avoidance of explicit affect. These texts are littered with attitude markers, indicating the writer's responses to material, pointing out what is important, unusual or valuable and encouraging readers to engage with the topic. Attitude in articles, moreover, tend to signal the writer's affiliation to shared disciplinary values while in blogs they often help to impart an informal tone and stress accessibility. Table 3 shows the distribution of the different functions of attitudinal markers in the two genres based on Dueñas' (2010) categories of assessment (i.e. acuity, novelty, interestingness, validity, quality), significance (i.e. relevance, importance) and emotion (i.e. emotional judgements).

Table 3 Types of attitude markers across genres (per 1,000 words \& \% of total)

\begin{tabular}{lcccc}
\hline \multirow{2}{*}{ Adjectival function } & \multicolumn{2}{c}{ Academic blog posts } & \multicolumn{2}{c}{ Journal articles } \\
\cline { 2 - 5 } & per 1,000 words & $\%$ & per 1,000 words & $\%$ \\
\hline Assessment & 9.65 & 65.65 & 4.35 & 55.27 \\
Significance & 3.76 & 25.60 & 3.04 & 38.55 \\
Emotion & 1.29 & 8.75 & 0.49 & 6.18 \\
Total & $\mathbf{1 4 . 7 0}$ & $\mathbf{1 0 0}$ & $\mathbf{7 . 8 8}$ & $\mathbf{1 0 0}$ \\
\hline
\end{tabular}

As we can see, all three types were more frequent in blogs, with the differences in assessment and emotion types statistically significant $(\log$ Likelihood $=31.60$, 
$\mathrm{p}<0.01$ for assessment and $9.75, \mathrm{p}<0.01$ for emotion). Once again, we see the hybridity of the genre here, as blog writers demonstrate their awareness of striking a balance between detached information, subjective evaluation and interpersonal negotiation. We can see affect working to convey writers' assessments (11 and 12) and emotions (13 and 14):

(11) The results were illuminating. (BP13)

(12) Nonetheless, our review did point to some promising themes and possible ways forward. (BP1)

(13) But strangely, universities have not explained their operations very well to members of the public. (BP12)

(14) Unfortunately, we did not hit on any winners. (BP21)

Stressing significance is, of course, a staple of journal research writing as authors attempt to demonstrate the importance of their claims to the discipline. But crafting texts which offer a positive evaluation of a result or entity shows how this is also vital in promoting the significance of their contributions to a wider audience, often with the added advantage of making it difficult to challenge.

Categorically asserting significance in this way thus constructs a relationship with readers along with an argument in the text, but this is a relationship where the writer is firmly in control.

\subsection{Self-mention}

How we understand writers and their attitudes to their arguments and readers is heavily influenced by their choice of authorial presence: the extent they intrude into their texts using first person (Hyland, 2004). The convention of avoiding the first person to convey an impersonal stance, once a sanctified principle for style guide writers and science 
authors, now seems less rigidly adhered to than in the past (Hyland \& Jiang, 2017).

However, Table 2 shows, once again, that self-mention was significantly more frequent in the blogs $(\log$ Likelihood=6.56, $\mathrm{p}<0.05)$. Self-mention is used in blogs to add a reflectional dimension to the writing process and allow the researcher to speak directly to the reader in an unmediated way. It is also a key marker of informality (e.g. Chang \& Swales, 1999) impart a sense of proximity between the writer and reader of the blog. This seems to be a rhetorical strategy which exploits the association blogs have with conversational sharing, presenting information and ideas through personal experience and an authoritative reliability rather than reliance on established measures of objective proof.

(15) Drawing on our experiences and perceptions, we hope to articulate the value and importance of mainstreaming boundary-spanners to cultivate a more dynamic relationship between science and policy. (BP3)

(16) We contend that boundary-spanning as a distinct practice can play a critical role in facilitating this contribution. (BP3)

This is, of course, closely associated with bloggers' desire to gain acceptance for ideas from a diverse and possibly unknown audience. It also enables writers to adopt a less threatening role and encourages a certain trust in readers. It is, then, is a deliberate contrast with much research writing, manipulating the digital medium for maximum effect.

However, it is also true that self-mention accounts for the lowest proportion of stance features in both genres. In journals, we can point, perhaps, to the objectivity and openmindedness of observations as facts, but the result is surprising for academic blogs, even those reviewed and edited for publication. A strong authorial presence might be expected in the blogs but we discovered that this personal voice is conveyed through other devices, most notably boosters and attitude markers, rather than self-mention. 


\section{The expression of engagement}

Engagement is the ways writers rhetorically acknowledge the presence of their readers. Whatever the genre, we have to recognise and include readers in our talk, reaching out to acknowledge them and let them know we are communicating with them, while, at the same time, positioning them and guiding them through a line of argument. Table 2 shows that engagement is less apparent in texts than stance and also presents a less straightforward picture, with pronouns, questions and personal asides most frequent in the blogs and directives and shared knowledge markers more common in journal articles. Bearing in mind these are much lower frequencies, we can see that questions showed the most marked difference, with four and a half times more cases in the blogs, but that reader pronouns accounted for the largest frequencies and proportion of engagement features. We explore these features below, focusing on reader-mention, directives and questions.

\subsection{Reader-mention}

Reader pronouns offer the most explicit ways of bringing readers into a discourse by directly referring to them (Hyland, 2008). They account for nearly half of all engagement markers in our blog corpus and significantly more than in the articles (log Likelihood=9.65, $\mathrm{p}<0.01$ ). Hyland and Jiang (2017) believe that reader pronouns have been in steady and widespread decline in research writing over the past 50 years, an avoidance they attribute to writers' reluctance to engage their interlocutors in such an explicitly direct and personal way, but blog writers have no such qualms. More references to the reader is a rhetorical strategy which borrows from more personal and dialogic forms of interaction, creating greater intimacy and proximity:

(17) This, in turn, will increase your chances in grant procedures and foster your career potential. (BP20)

(18) This is what we, as researchers and advisors in think tanks and governmental organisations, have reflected on and -yes - learnt in the early years of implementing large climate change research programmes such as PRISE, BRACED and CARIAA. 
(BP9)

The general perception of the blog as a genre for self-expression, together with the more general readership of the academic variety, means writers must adjust the ways they present information. Here the use your (in 17), for example, refers to the reader as someone much like the writer, who can see the reasonableness of the statement, while inclusive we (example 18) evokes a sense of shared understandings and rapport between writers and diverse audiences, reflecting a co-operative ethos.

There are also differences between the two corpora when looking at the different types of reader pronouns used. Table 4 shows that inclusive first person pronouns were much more frequent in the blogs and with a far higher proportion of all forms. This genre difference, also noted by Luzón (2013a), demonstrates writers' attempts to involve readers and generally head-off divergent views. This goal takes on added importance in blogs where writers, working outside a disciplinary medium and framework of assured knowledge, are less certain about what knowledge they may share with readers. As a result, they often fall back on an assumed personal familiarity with a shared natural and social world.

Table 4: reader pronouns across genres (per 1,000 words \& percentage of total)

\begin{tabular}{lcccc}
\hline \multirow{2}{*}{ Form of } & \multicolumn{2}{c}{ Academic blog posts } & \multicolumn{2}{c}{ Research articles } \\
\cline { 2 - 5 } pronoun & per 1,000 words & $\%$ & per 1,000 words & $\%$ \\
\hline we/our/us & 2.99 & 56.36 & 0.70 & 35.28 \\
you/your & 1.74 & 32.73 & 0.63 & 31.39 \\
one/reader & 0.58 & 10.91 & 0.66 & 33.33 \\
Total & $\mathbf{5 . 3 1}$ & $\mathbf{1 0 0 . 0 0}$ & $\mathbf{1 . 9 9}$ & $\mathbf{1 0 0 . 0 0}$ \\
\hline
\end{tabular}

We also find you and your to be more common in blogs (per 1,000 words). Once again, these are forms which characterize conversational intimacy, face-to-face spoken 
discourse and personal emails (Blanchard, 2011), allowing writers to engage readers more closely by borrowing the features of informal registers. This is a highly interactive form and contrasts with the low frequencies of the more formal one, the only form more common in articles. Directly addressing the reader in such a direct and personal way is particularly effective when combined with rhetorical questions or directives, as here:

(19) Relationships don't appear out of thin air, though, so where do you start? (BP5)

(20) Do you think these criteria signify academic excellence? (BP7)

(21) But what do we mean by learning? Learning by whom and about what? (BP9)

So while often avoided by researchers in social science journals articles, second person hits exactly the right tone when they transform their work into blogs.

\subsection{Directives}

Directives instruct the reader to perform an action or to see things in a way determined by the writer: they therefore help manage the readers' understanding and processing of a text and modify writer-reader relations (Hyland, 2002a). They are generally expressed through obligation modals (must, should have to) and imperatives (note, consider, imagine) and tend to be less common in social science texts (Hyland, 2002a). We also found they are significantly less frequent in the blogs than the journal articles (log Likelihood $=4.62, \mathrm{p}<0.1)$.

The reason for this seems quite straightforward: directives introduce readers into the text in order to move them in a particular direction, often focusing their attention, emphasizing important points and sometimes telling them how they should understand a certain finding. Because of this they carry a certain amount of interpersonal risk. Claiming the authority to instruct readers in this way may serve to undermine the affiliative tenor which blogs tend to evoke and depend on and this risks weakening the writer's proximity to the audience and endangering the success of the claims he or she is 
making.

(22) Consider whether they may have relevant connections and ask whether they feel comfortable making an introduction for you. (BP5)

(23) Be sure, however, to treat these hard-won connections with care and respect. (BP25)

As we saw above, engagement features also often combine with reader-mention to increase the impact of the statement, bringing writer and reader into closer rhetorical proximity and closer to agreement:

(24) You have to take the disciplinary circumstances into account when it comes down to the nitty gritty details of open science and what it means for an individual researcher. (BP26)

A sensibility to an unknown readership, many of whom are likely to be from outside the author's disciplinary community, means that such strong directives, instructing them to see things in a certain way, may be regarded as too bald-on-record to be a useful engagement strategy.

More frequent than such reader-positioning 'cognitive acts' in blogs are what Hyland (2002a) calls 'physical acts', which ask readers to carry out some real-world action. Table 5 summarises the preferred types of directive in the two genres.

Table 5 Proportion of directives across genres (per 1,000 words $\& \%$ of total)

\begin{tabular}{lcccc}
\hline & \multicolumn{2}{c}{ Academic blog posts } & \multicolumn{2}{c}{ Journal articles } \\
\cline { 2 - 5 } & per 1,000 words & $\%$ & per 1,000 words & $\%$ \\
\hline Textual act & 0.23 & 15.22 & 0.57 & 30.56 \\
Physical act & 0.68 & 45.65 & 0.60 & 32.05 \\
Cognitive act & 0.58 & 39.13 & 0.70 & 37.39 \\
Total & $\mathbf{1 . 4 8}$ & $\mathbf{1 0 0 . 0 0}$ & $\mathbf{1 . 8 7}$ & $\mathbf{1 0 0 . 0 0}$ \\
\hline
\end{tabular}


Physical acts seem to benefit from the on-line immediacy of blogs which enables reseders to have a sense of how research procedures take place step by step, and how results gradually come into view (Mauranen, 2013). This leads to more personal accounts of research activities or which simulate real-word actions.

(25) Scientists can and should use exit or voice to reform these institutions or establish better alternatives. (BP19)

(26) Within such re-evaluation, we need to stop treating "the market" as a natural force. (BP16)

(27) There are new frontiers for academic publishing but scholarly associations and faculty must seize the opportunities. (BP19)

But while the genre differences for cognitive and physical directives were not statistically significant, those for textual acts were $(\log$ Likelihood $=5.05, \mathrm{p}<0.07)$. In published research writing authors present their arguments supported by tables, figures and other graphical paraphernalia which requires intratextual references together with citations to demonstrate the novelty of claims and their relationship to past work (Hyland, 2015). As a result, we might expect journal articles to contain more directives referring readers to other texts or to other parts of the same text. Academic blog posts, on the other hand, particularly in this case, have severe word limits which place considerable constraints on the inclusion of such material. Moreover, at least in the social sciences, blogs are written for an audience which expects less citational and diagrammatic support for claims. The presentation of information, and hence persuasion, are managed differently in this genre. Where this kind of backing is needed, the affordances of blogs allow it to be embedded in the structure of the medium itself, through hyperlinks to research papers, images and video clips.

Once again, both the purpose and the audience of the genre help account for different 
rhetorical choices, argument patterns and forms of interaction with readers.

\subsection{Questions}

The last engagement feature we want to draw attention to here in any detail is the much higher use of questions in the blogs $(\log$ Likelihood $=20.72, \mathrm{p}<0.01)$. Questions are perhaps the main strategy of dialogic engagement, inviting the involvement of readers and bringing them into the discussion as participants (Hyland, 2002b). They are, however, rarely used in journal articles as they tend to be rhetorical and simply serve to highlight an imbalance of knowledge between participants. Writers are perhaps wary of them as readers recognize they are a persuasive strategy designed to manoeuvre them into agreement with the writer. The very different interpersonal context of blogs, on the other hand, seems to make questions less obviously obtrusive and manipulative.

The more egalitarian, personal context of blogs provides an environment in which questions seem more natural and less misplaced, yet despite this, almost all were rhetorical, allowing the writer to immediately present his or her viewpoint.

(28) Does this mean that influencing policy is out of our control, and we might as well give up now? Definitely not! (BP5)

(29) How does one identify common areas of focus when there are a wide range of possibilities, themes and contexts? There are no shortcuts. (BP9)

Less directly forceful than a blunt assertion, questions clearly play an important role for blog writers, being 4 times more common in posts. Questions allow researchers to move away from a monologue and turn a one-sided exposition into a dialogue, recruiting readers into a virtual debate. This helps to manufacture immediacy and informality, which thus helps make the specialised knowledge more intelligible and informative and the argument more explicitly negotiable.

Despite the low frequencies, we also noticed that questions seemed to be used 
differently in the two corpora. In academic blog posts, as in (28) and (29), writers almost always provide answers to their questions immediately to directly underscore their own evaluation and draw their audiences deeper into the arguments. We also found writers using them as real questions to end the blog with a flourish, leaving the reader with a sense of an important ongoing issue:

(30) However, we only have the benefit of hindsight because we conducted the pilot experiment. Imagine what would have happened if the town simply took our advice and created an expensive training program? (BP21)

In journal articles, however, questions were often research questions, used to provide readers with a sense of direction or to seek disciplinary their collaboration in exploring an unresolved research issue:

(31) We have argued, for instance, that nested programmes offer novel opportunities to scale up effective approaches, but are there limits to the scale at which certain learning processes can be effectively applied? (RA9)

While we expect the writer to go on and answer this, there is a greater sense of shared exploration and an appeal to shared disciplinary knowledge.

\subsection{Other engagement features}

The remaining engagement features are far less common in the two genres and we will just mention them briefly.

Appeals to shared knowledge are often used to position readers within the apparently naturalized boundaries of disciplinary understandings (Hyland, 2001) and this helps account for the fact they are significantly more common in journal articles (log Likelihood $=6.05, \mathrm{p}<0.05$ ). Explicitly referring to shared knowledge is a preferred way of engaging readers in our journal corpus as writers seek to bring readers to agreement by explicitly building solidarity with them as members of the same community. The diverse readership of blogs makes this an unrealistic strategy, more likely to exclude non-specialists than engage them. 
Personal asides, on the other hand, are more frequent in blogs, although the numbers are too small to show any significant difference. Asides allow writers to address readers directly by briefly interrupting the argument to offer a comment on what has been said (Hyland, 2005). We might have expected blog writers to make more use of this strategy, but while common in informal conversation, it appears that these blogs are, in part, an academic genre.

\section{Discussion and conclusion}

We have explored how writers recontextualize, in academic blogs, material they have recently published in journal articles for a new audience. Among the more obvious changes that occur, such as a massively reduced text length and fewer trappings of academic support such as citations, tables and graphs, are those concerning writerreader relations. The ways that writers intervene in these blogs to present themselves, their work and their readers reflect a sensitivity to new purposes and a context where the readership is less homogeneous and predictable. Most importantly, this means adjusting the strength of assertions with appropriate boosting and hedging to ensure readers see the novelty and importance of the claims made but do not respond over-critically to them; adding affective commentary on what is said; intruding more often using first person; bringing readers into the text by mentioning them more often and addressing them with questions. In sum, they deploy linguistic features which are more personal and evaluative than we find in articles and which, in combination, create a sense of proximity and dialogic exchange.

Clearly, the blog offers academics considerable advantages. This is an opportunity to present themselves and promote their work to wider audiences beyond the narrow confines of their discipline. But in addition to the advantages of sharing academic knowledge, blogs help academics promote a different and increasingly valued side to themselves: as publicly-minded intellectuals contributing to the wider understanding of science and to chipping away at the perception of universities as out-of-touch ivory towers. Communication to a public audience is part of both popularising and 
democratising science as well as meeting current imperatives requiring public institutions to be accountable and value for money.

This is, of course, a relatively small-scale study of only 30 texts in each genre, and more needs to be done in this area. Further work might explore the individual transformations made by authors in the process of recontextualization, for example, and the public responses made by readers of academic blogs. Our results show, however, that participation in this new arena can be challenging for academics who, steeped in the lore and arcane rhetorical conventions of formal academic discourse, must not only familiarize themselves with the affordances of new digital genres, but blend discursive practices from both academic and popular registers to achieve their rhetorical purposes.

The reformulation of academic propositions not only involves reframing knowledge, but reconstructing writer-reader interactions to suit new conditions. It requires bloggers to adopt a, perhaps unfamiliar, informality in their writing by the use of self-reference, openly evaluative and affective commentary and imagining the co-presence of heterogeneous readers. Responses are quick to appear, sometimes critical and often blunt, encouraging circumspection tempered with the need to convey ideas with conviction and authority. These features mean that blogs are like no other academic genre writers may be familiar with, such as peer reviews and book reviews, and require a very different orchestration of rhetorical resources.

\section{Acknowledgments}

We would like to express our thanks to Prof. Maria Kuteeva, Dr. María José Luzón and Dr. Carmen Sancho Guinda for their constructive comments on an earlier version of this paper.

\section{Funding}

This work is supported by the China Scholarship Council under grant number 201806140042. 


\section{References}

Andrews, P. (2003). Is blogging journalism? Nieman Reports, 57(3), 63-65.

Angouri, J. \& Tseliga, T. (2010). "You have no idea what you are talking about!" From e-disagreement to e-impoliteness in two online fora. Journal of Politeness Research. Language, Behaviour, Culture, 6 (1), 57-82.

Anthony, L. (2018). AntConc (Version 3.5.7) [Computer Software]. Tokyo, Japan: Waseda University. Retrieved from: http://www.laurenceanthony.net/software.html

Bernstein, B. (1990). Class, codes and control. Vol. 4: the structuring of pedagogic discourse. London: Routledge.

Biber, D. (2006). University language: A corpus-based study of spoken and written registers. Amsterdam, Netherlands: John Benjamins.

Biber, D., \& Finegan, E. (1989). Styles of stance in English: lexical and grammatical marking of evidentiality and affect. Text, 9(1), 93-124.

Blanchard, A. (2011). Science blogs in research and popularization of science: Why, how and for whom?. In M. Cockell, J. Billotte, F. Darbellay \& F. Waldvogel (Eds.), Common knowledge: The challenge of transdisciplinarity (pp. 219-232). Lausanne, Switzerland: EPFL Press.

Bondi, M. (2018). Try to prove me wrong: dialogicity and audience involvement in economics blogs. Discourse, Context \& Media, 24, 33-42.

Chang, Y.-Y. \& Swales, J. (1999). Informal elements in English academic writing: Threats or opportunities for advanced non-native speakers? In C. Candlin, \& K. Hyland (Eds.), Writing: Texts, processes and practices (pp. 145-167). London: Longman.

Dueñas, P. M. (2010). Attitude markers in business management research articles: a cross-cultural corpus-driven approach. International Journal of Applied Linguistics, 20(1), 50-72.

Elmes, J. (2012). LSE Bloggers Divine the Future of Academia in European Politics. Retrieved from: https://www.questia.com/read/1P32687970771/lsebloggers- divine-the-future-of-academia-in-european 
Gotti, M. (2014). Reformulation and recontextualization in popularization discourse, Ibérica, 27, 15-34.

Grafton, K. (2009). Situating the public social actions of blog posts. In J. Giltrow \& D. Stein (Eds.), Genres in the Internet (pp. 85-111). Amsterdam, Netherlands: Benjamins.

Gray, B., \& Biber, D. (2012). Current conceptions of stance. In K. Hyland \& C. SanchoGuinda (Eds.), Stance and voice in written academic genres (pp. 15-33). London, UK: Palgrave.

Gross, A. \& Buehl, J. (2015). Science and the internet: Communicating knowledge in a digital age. Amityville, NY: Baywood.

Hood, S. (2010). Appraising Research: Evaluation in Academic Writing. New York: Palgrave Macmillan.

Hyland, K. (1998). Hedging in scientific research articles. Amsterdam: John Benjamins.

Hyland, K. (2001). Bringing in the Reader: Addressee Features in Academic Writing. Written Communication, 18(4), 549-574.

Hyland, K. (2002a). Directives: Argument and engagement in academic writing. Applied Linguistics, 23(2), 215-239.

Hyland, K. (2002b). What do they mean? Questions in academic writing. TEXT, 22(4), $529-557$.

Hyland, K. (2004). Disciplinary discourses: Social interactions in academic writing. Michigan: University of Michigan Press.

Hyland, K. (2005). Stance and engagement: A model of interaction in academic discourse. Discourse Studies, 7(2), 173-192.

Hyland, K. (2008). Persuasion, interaction and the construction of knowledge: Representing self and others in research writing. International Journal of English Studies, 8(2), 1-23.

Hyland, K. (2015). Academic publishing: issues and challenges in the construction of knowledge. Oxford: OUP. 
Hyland, K. \& Jiang, F. K. (2016). Change of attitude? A diachronic study of stance. Written communication, 33(3), 251-274.

Hyland \& Jiang, F. K. (2017). Is academic writing becoming more informal?. English for Specific Purposes, 45, 40-51.

Kleinke, S. (2008). Emotional commitment in public political internet message boards. Journal of Language and Social Psychology, 27 (4), 409-421.

Kouper, I. (2010). Science blogs and public engagement with science: Practices, challenges, and opportunities. Journal of Science Communication, 9(1), 1-10.

Kuteeva, M. (2016). Research blogs, tweets, and wikis. In: K. Hyland \& P. Shaw (Eds.), The Routledge Handbook of English for Academic Purposes (pp. 433-445). Routledge, London.

Lehti, L. (2011). Blogging politics in various ways: A typology of French politicians' blogs. Journal of Pragmatics, 43, 1610-1627.

Linell, P. (1998). Discourse across boundaries: on recontextualisation and the blending of voices in professional discourse. Text \& Talk, 18(2), pp. 143-157.

Luzón, M. J. (2011). Interesting post, but I disagree: Social presence and antisocial behavior in academic weblogs. Applied linguistics, 32(5), 517-540.

Luzón, M. J. (2013a). Public communication of science in blogs: Recontextualizing scientific discourse for a diversified audience. Written Communication, 30(4), 428-457.

Luzón, M. J. (2013b). This is an erroneous argument: Conflict in academic blog discussions. Discourse, Context \& Media, 2(2), 111-119.

Luzón, M. J. (2018). Features of online ELF in research group blogs written by multilingual scholars. Discourse, Context Media, 24, 24-32.

Mahrt, M. \& Puschmann, C. (2014). Science blogging: an exploratory study of motives, styles, and audience reactions. Journal of Science Communication, 13(3), 1-17.

Martin, J. R., \& White, P. R. R. (2005). The language of evaluation: Appraisal in English. Houndmills, UK: Palgrave Macmillan.

Mauranen, A. (2013). Hybridism, edutainment, and doubt: Science blogging finding its feet. Nordic Journal of English Studies, 13(1), 7-36. 
Mauranen, A. (2016). Reflexively speaking. Walter de Gruyter.

McGrath, L. (2016). Open-access writing: An investigation into the online drafting and revision of a research article in pure mathematics. English for Specific Purposes, $43,25-36$.

Myers, G. (2010). The discourse of blogs and wikis. London, UK: Continuum.

Smart, G. (2016). Discourse coalitions, science blogs, and the public debate on global climate. In A. S. Bawarshi \& M. J. Reiff (Eds.), Genre and the performance of publics (pp. 157-177). Boulder, CO: Utah State University Press.

Tokar, A, et al. (2012). Science and the Internet: Introduction. In Tokar, A, Beurskens, M., Keuneke, S., Mahrt, M., Peters, I., Puschmann, C., van Treeck, T. (Eds.), Science and the Internet (pp. 1-9). Düsseldorf: Düsseldorf University Press.

Trench, B. (2008). Internet: Turning science communication inside-out. In Bucchi, M. \& Trench, B. (Eds.), Handbook of public communication of science and technology. London, UK: Routledge, pp. 185-198.

Vassileva, I. (2001). Commitment and detachment in English and Bulgarian academic writing. English for specific purposes, 20, 83-102.

Walker, J. (2006). Blogging from inside the Ivory Tower. In A. Bruns \& J. Jacobs (Eds.), Uses of blogs (pp. 127-138). New York: Peter Lang. 